\title{
Enhancement of cytotoxic effects of gemcitabine by Dclk1 inhibition through suppression of Chk1 phosphorylation in human pancreatic cancer cells
}

\author{
DAICHI KAWAMURA ${ }^{1}$, YOSHIHIRO TAKEMOTO ${ }^{1}$, ARATA NISHIMOTO $^{2}$, \\ KOJI UENO $^{1}$, TOHRU HOSOYAMA ${ }^{1}$, BUNGO SHIRASAWA ${ }^{2}$, TOSHIKI TANAKA ${ }^{1}$, \\ NARUJI KUGIMIYA ${ }^{1}$, EIJIRO HARADA ${ }^{1}$ and KIMIKAZU HAMANO ${ }^{1}$ \\ Departments of ${ }^{1}$ Surgery and Clinical Sciences, ${ }^{2}$ Medical Education, Yamaguchi University \\ Graduate School of Medicine, Ube, Yamaguchi 755-8505, Japan
}

Received December 29, 2016; Accepted July 17, 2017

DOI: $10.3892 /$ or.2017.5974

\begin{abstract}
Although gemcitabine (GEM) is frequently used in the treatment of pancreatic cancer, the effects are limited. To increase the inhibitory effect of GEM, the identification of a molecular target is needed. Recent studies have revealed that doublecortin-like kinase 1 (Dclk1) positively regulates tumor growth, invasion, metastasis, factors related to epithelialmesenchymal transition (EMT), pluripotency, angiogenesis, and anti-apoptosis in pancreatic cancer cells. Therefore, Dclk1 is a potential therapeutic target for pancreatic cancer. However, the Dclk1-signaling pathway including its substrate proteins remains to be elucidated. To identify the candidate substrate proteins phosphorylated by Dclk1, we performed a cancer-related phosphorylated protein microarray using Dclk1-inhibited MIA Paca2 cells. Expression levels of phosphorylated cdc25A (p-cdc25A) and phosphorylated Chk1 (p-Chk1), belonging to the ATR pathway, were decreased by treatment with Dclk1 inhibitor LRRK2-IN-1 (LRRK), indicating Dclk1 involvement in the ATR pathway. Consistent with this finding, the GEM-induced p-Chk1 expression was significantly decreased by treatment with LRRK. Notably, combined treatment with GEM and LRRK allowed cell cycle progression without arresting at $\mathrm{S}$ phase, while individual treatment with GEM induced cell cycle arrest at $\mathrm{S}$ phase. In addition, combined treatment with GEM and LRRK increased
\end{abstract}

Correspondence to: Dr Yoshihiro Takemoto, Department of Surgery and Clinical Science, Yamaguchi University Graduate School of Medicine, 1-1-1 Minami-Kogushi, Ube, Yamaguchi 755-8505, Japan

E-mail: ytake@yamaguchi-u.ac.jp

Dr Arata Nishimoto, Department of Medical Education, Yamaguchi University Graduate School of Medicine, 1-1-1 Minami-Kogushi, Ube, Yamaguchi 755-8505, Japan

E-mail: anishimo@yamaguchi-u.ac.jp

Key words: Dclk1, pancreatic cancer, gemcitabine, Chk1, cell cycle, DNA repair inhibition the number of $\gamma$-H2AX-positive cells compared with that upon individual treatments. Moreover, LRRK alone, and combined treatment with GEM and LRRK, induced caspase-3 activation and PARP1 cleavage, in contrast to treatment with GEM alone. Finally, combined treatment with GEM and LRRK significantly reduced cell survival compared to individual treatment with GEM. These results indicate that Dclk1 inhibition in combination with GEM treatment offers a novel approach to treat pancreatic cancer cells.

\section{Introduction}

Pancreatic cancer is one of the lethal malignancies, and the 5 -year survival rate for pancreatic cancer is only $8 \%$ (1). Although surgical resection is regarded as the effective treatment for cure, gemcitabine (GEM) is often used as a standard anticancer drug following surgical resection (2). The treatment of GEM, a nucleoside analogue, induces cell cycle arrest at $S$ phase (3) and triggers the phosphorylation of checkpoint kinase 1 (Chk1), a cell cycle checkpoint protein (4,5). Since it has been expected that GEM treatment and Chk1 inhibition are likely to increase cell death owing to lethal chromosomal instability caused by cell cycle progression without repairing damaged DNA at the arrested $S$ phase, this combined effect has been examined. As expected, this combined treatment inhibits colony formation (4), increases clonogenic cell death (6) and inhibits tumor growth compared with GEM treatment alone (7-10). Phase I clinical trials have been initiated, and the recommended phase II dose has been shown (11-15). However, concerns about unpredicted effects of Chk1 inhibitors on normal cells have been raised $(12,16)$. Therefore, to increase the inhibitory effect of GEM without causing side effects on normal cells, the identification of a molecular target specific for cancer cells is necessary.

Doublecortin-like kinase 1 (Dclk1) encodes a $\mathrm{Ca}^{2+} /$ calmodulin-dependent kinase (CaM kinase)-like domain and regulates microtubule polymerization $(17,18)$. Dclk1 is highly expressed in human pancreatic cancer compared with human normal pancreas (19) and positively regulates tumor growth, invasion, metastasis, pluripotency factors, angiogenic 
factors, and epithelial-mesenchymal transition (EMT)-related genes in pancreatic cancer cells (20-22). Two small molecule kinase inhibitors, XMD8-92 and LRRK2-IN-1 (LRRK), inhibit tumor growth and the expression levels of EMT-, pluripotency-related genes, and oncogenes such as $c-M Y C$ and $K R A S$ through Dclk1 inhibition $(23,24)$. However, the Dclk1signaling pathway, including its substrate proteins, remains to be elucidated.

In this study, we identified Chk1 as a candidate substrate protein phosphorylated by Dclk1, using a cancer-related phosphorylated protein microarray. We examined the effects of GEM, LRRK, and combined treatment with GEM and LRRK on p-Chk1 expression, DNA damage, apoptosis, and cell survival rate in pancreatic cancer cells.

\section{Materials and methods}

Cell lines and culture. The human pancreatic cancer-derived cell lines MIA Paca2 and PANC-1 were purchased from Riken BioResource Center (Tsukuba, Japan) and maintained in DMEM and RPMI-1640, respectively, with $10 \%$ fetal bovine serum (FBS) at $37^{\circ} \mathrm{C}$ in a humidified atmosphere containing $5 \% \mathrm{CO}_{2}$.

Reagents. LRRK2-IN-1 was purchased from Merck Millipore (Darmstadt, Germany) and dissolved in dimethyl sulfoxide (DMSO). Gemcitabine was purchased from Sigma-Aldrich (Tokyo, Japan) and dissolved in PBS. LRRK2-IN-1 and gemcitabine were stored at $4^{\circ} \mathrm{C}$.

Transfection of siRNAs. siRNAs were synthesized by GE Dharmacon (Chalfont, UK). Transfection of On-Target plus Human DCLK1 (9201) siRNA-SMART pool (L-004884-000005) or On-Target plus Non-targeting Pool (D-001810-10-05) control siRNA was performed with Lipofectamine RNAiMAX (Invitrogen, Carlsbad, CA, USA) following the manufacturer's protocol. Following incubation for $72 \mathrm{~h}$, PANC-1 cells transfected with Non-target or Dclk1 siRNA were harvested to prepare cell lysates.

Protein microarray. To identify proteins phosphorylated by Dclk1, we used a protein microarray, Cancer Signaling Phospho Antibody Array (Full Moon BioSystems Inc., Sunnyvale, CA, USA). This array features 269 highly specific antibodies that are important in cancer signaling pathways. Cell lysates prepared from MIA Paca2 cells treated with DMSO or LRRK2-IN-1 were used, as well as PANC-1 cells transfected with non-target or Dclk1 siRNA. The arrays were scanned using GenePix 4000B microarray scanner (Molecular Devices, Sunnyvale, CA, USA), and array images were analyzed with GenePix Pro7.

Western blot analysis. MIA Paca2 cells were treated with DMSO, GEM (20 or $40 \mathrm{nM})$, LRRK $(10 \mu \mathrm{M})$ treatment, or the combined treatment with GEM (20 or $40 \mathrm{nM}$ ) and LRRK $(10 \mu \mathrm{M})$ for $48 \mathrm{~h}$.PANC-1 cells were transfected with Non-target or Dclk1 siRNA and incubated for $72 \mathrm{~h}$. After harvesting, the cells were lysed with RIPA buffer [50 mM Tris- $\mathrm{HCl}(\mathrm{pH} 7.4)$, $150 \mathrm{mM} \mathrm{NaCl}, 1 \% \mathrm{NP} 40,0.5 \%$ sodium deoxycholate, $0.1 \%$ SDS, and $1 \mathrm{X}$ protease inhibitor] and incubated on ice for
Table I. The expression of phosphorylated proteins which decreased by $>50 \%$ in Dclk1-inhibited MIA Paca2 cells.

\begin{tabular}{|c|c|c|c|}
\hline \multirow[b]{2}{*}{ Antibody name } & \multicolumn{2}{|c|}{ Intensity } & \multirow{2}{*}{$\begin{array}{c}\text { Ratio (\%) } \\
\text { (LRRK/ } \\
\text { Control) }\end{array}$} \\
\hline & $\begin{array}{c}\text { Control } \\
\text { (DMSO) }\end{array}$ & $\begin{array}{c}\text { LRRK } \\
(50 \mu \mathrm{M})\end{array}$ & \\
\hline Akt (Phospho-Ser473) & 15278.5 & 500.5 & 3.28 \\
\hline cdc25A (Phospho-Ser75) & 26021.0 & 1914.0 & 7.36 \\
\hline STAT1 (Phospho-Ser727) & 27948.0 & 2471.0 & 8.84 \\
\hline JAK2 (Phospho-Tyr221) & 16696.0 & 1557.0 & 9.33 \\
\hline FAK (Phospho-Tyr925) & 18429.0 & 3475.0 & 18.86 \\
\hline c-Jun (Phospho-Ser243) & 18280.5 & 4807.0 & 26.30 \\
\hline cdc25C (Phospho-Ser216) & 19121.5 & 5211.0 & 27.25 \\
\hline BAD (Phospho-Ser112) & 23047.5 & 7167.0 & 31.10 \\
\hline NFkB-p105/p50 (Phospho-Ser893) & 12876.5 & 4189.0 & 32.53 \\
\hline eEF2K (Phospho-Ser366) & 17454.5 & 5932.0 & 33.99 \\
\hline JAK2 (Phospho-Tyr1007) & 12732.0 & 5130.0 & 40.29 \\
\hline CDK2 (Phospho-Thr160) & 17259.0 & 6985.0 & 40.47 \\
\hline BCL-2 (Phospho-Ser70) & 16820.0 & 6861.0 & 40.79 \\
\hline Raf1 (Phospho-Ser259) & 15261.5 & 6241.5 & 40.90 \\
\hline TYK2 (Phospho-Tyr1054) & 16798.0 & 7063.0 & 42.05 \\
\hline BCL-2 (Phospho-Thr56) & 14397.5 & 6312.5 & 43.84 \\
\hline c-Jun (Phospho-Thr239) & 11045.5 & 5136.0 & 46.50 \\
\hline NFkB-p105/p50 (Phospho-Ser907) & 23004.5 & 11145.5 & 48.45 \\
\hline Chk1 (Phospho-Ser280) & 17482.0 & 8578.5 & 49.07 \\
\hline
\end{tabular}

$30 \mathrm{~min}$. After centrifugation at $20000 \mathrm{x} \mathrm{g}$ for $20 \mathrm{~min}$ at $4^{\circ} \mathrm{C}$, and the supernatants were collected as cell lysates. Protein concentrations were determined by BCA protein assay (Thermo Fisher Scientific, Waltham, MA, USA). Equivalent amounts of cell lysates $(30 \mu \mathrm{g})$ were mixed with sample buffer containing reducing reagent (Nacalai Tesque, Kyoto, Japan) and incubated at room temperature for $20 \mathrm{~min}$. Cell lysates mixed with sample buffer were separated by SDS-PAGE using polyacrylamide gel, SuperSep Ace 10 or 15\% (Wako, Osaka, Japan) and transferred to an Immobilon-P PVDF transfer membrane (Merck Millipore). After blocking with TBST (Tris-buffered saline containing Tween-20) including $5 \% \mathrm{w} / \mathrm{v}$ bovine serum albumin for $1 \mathrm{~h}$ at room temperature, the membrane was immunoblotted with the appropriate primary antibodies diluted at 1:1000 and incubated overnight at $4^{\circ} \mathrm{C}$. After washing, the membrane was incubated with the appropriate secondary antibodies conjugated with horseradish peroxidase diluted at 1:5000 for $45 \mathrm{~min}$ at room temperature. After washing, the immune complexes reacted with Amersham ECL Prime Western blotting detection reagent (GE Healthcare Life Sciences, Chicago, IL, USA) were detected using an Amersham Imager 600 (GE Healthcare Life Sciences). Band intensity was measured using ImageJ software.

The primary antibodies used in this study were antiDCAMKL1 antibody (Abgent, San Diego,CA, USA), anti-Chk1 antibody (Abcam, Cambridge, UK), anti-Phospho-Chk1 (S345) antibody (Cell Signaling Technology, Danvers, MA, USA), antiPARP-1 (F-2) antibody (Santa Cruz Biotechnology, Santa Cruz, CA, USA), anti-Caspase-3 (31A1067) antibody (Santa Cruz 


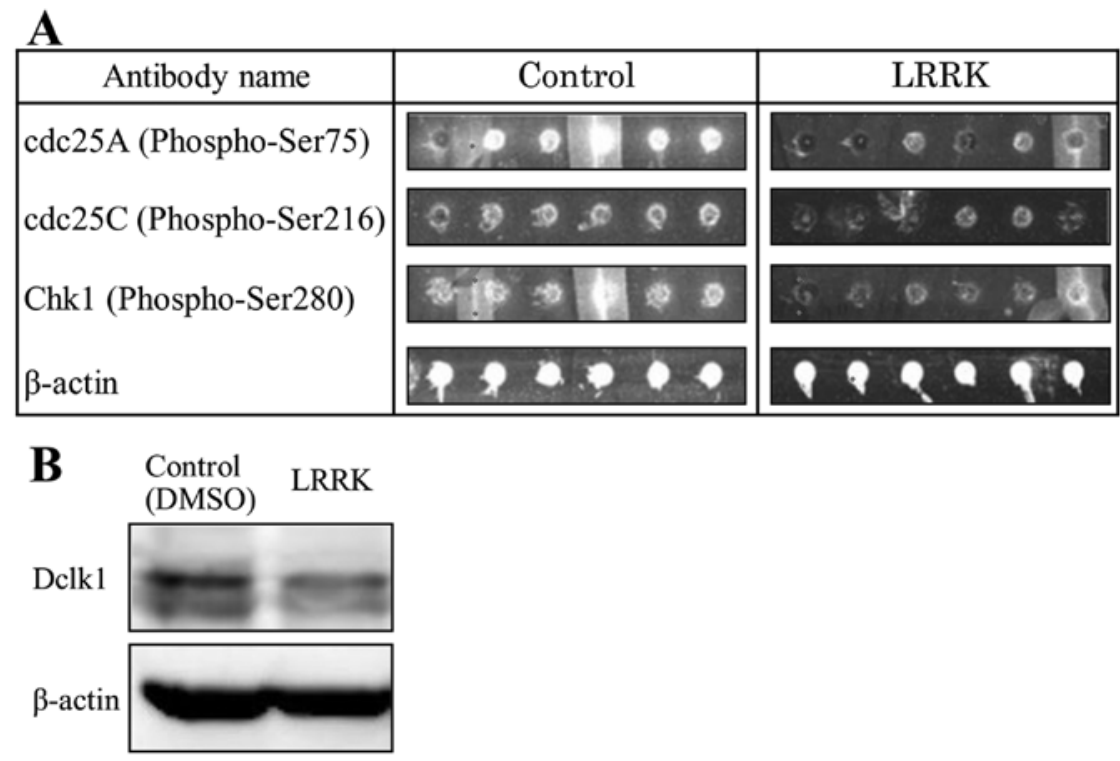

Figure 1. Screening of candidate substrate proteins phosphorylated by Dclk1, using protein microarray. (A) Cell lysates were prepared from MIA Paca2 cells treated with DMSO or LRRK $(40 \mu \mathrm{M})$ for $48 \mathrm{~h}$, followed by protein microarray. The array images of cdc25A (Phospho-Ser75), Chk1 (Phospho-Ser317), and $\beta$-actin in MIA Paca2 cells treated with DMSO or LRRK are shown. (B) The expression levels of Dclk1 and $\beta$-actin were detected by western blotting using the same lysates as protein microarray. $\beta$-actin was used to assess the total amount of proteins loaded on the gel.

Table II. Expression of the phosphorylated proteins which decreased by $>50 \%$ in Dclk1-silenced PANC-1 cells.

\begin{tabular}{lccc}
\hline & \multicolumn{2}{c}{ Intensity } & Ratio (\%) \\
\cline { 2 - 3 } Antibody name & $\begin{array}{c}\text { Control } \\
\text { (non-target) }\end{array}$ & si-Dclk1 & $\begin{array}{c}\text { (si-Dclk1/ } \\
\text { Control) }\end{array}$ \\
\hline cdc25A (Phospho-Ser75) & 14935.2 & 3961.8 & 26.53 \\
Fak (Phospho-Tyr397) & 13761.0 & 4523.5 & 32.87 \\
STAT4 (Phospho-Tyr693) & 10683.7 & 4292.0 & 40.17 \\
Chk1 (Phospho-Ser317) & 19384.0 & 8719.8 & 44.98 \\
PTEN (Phospho-Ser380/ & 13016.7 & 6084.8 & 46.75 \\
Thr382/Thr383) & & & \\
Src (Phospho-Tyr529) & 25736.5 & 12031.7 & 46.75 \\
\hline
\end{tabular}

si-Dclk1, Dclk1 siRNA.

Biotechnology), and anti- $\beta$-actin antibody (Sigma-Aldrich, St. Louis, MO, USA). The secondary antibodies used in this study were goat polyclonal anti-mouse immunoglobulins and anti-rabbit immunoglobulins conjugated with horseradish peroxidase (HRP) (Dako, Glostrup, Denmark).

Flow cytometry and cell cycle analysis. MIA Paca2 cells were seeded at $2 \times 10^{5}$ cells $/ 2 \mathrm{ml}$ media in each well of a 6-well plate. To synchronize cells at G0 phase of cell cycle, DMEM containing 10\% FBS was substituted with serum-free DMEM on the following day. After serum starvation for $24 \mathrm{~h}$, serum-free DMEM was substituted with DMEM containing $10 \%$ FBS, and cells were treated with DMSO, GEM $(40 \mathrm{nM})$, LRRK $(10 \mu \mathrm{M})$ treatment, or the combined treatment with GEM $(40 \mathrm{nM})$ and LRRK $(10 \mu \mathrm{M})$ for $24 \mathrm{~h}$. After harvesting, cells were fixed with $70 \%$ ethanol and incubated for $30 \mathrm{~min}$ at $-20^{\circ} \mathrm{C}$, followed by washing three times with Cell Staining Buffer (BioLegend, San Diego, CA, USA). Cells were incubated with propidium iodide (PI)/RNase (Immunostep, Salamanca, Spain) and FITC anti-H2A.X Phospho (Ser139) antibody (BioLegend, San Diego, CA, USA). After incubation, the cells were applied to a BD FACSAria III flow cytometer (BD Biosciences, San Jose, CA, USA).

Cell survival assay. MIA Paca2 cells were seeded at $1 \times 10^{4}$ cells/well on 96-well plates. After incubation for $24 \mathrm{~h}$, cells were treated with DMSO, GEM $(40 \mathrm{nM})$, LRRK $(10 \mu \mathrm{M})$ treatment, or the combined treatment with GEM $(40 \mathrm{nM})$ and LRRK $(10 \mu \mathrm{M})$ for $72 \mathrm{~h}$ and analyzed by Cell Count Reagent SF (Nacalai Tesque). To evaluate the number of viable cells, absorbance at $450 \mathrm{~nm}$ was measured using an iMark microplate reader (Bio-Rad, Hercules, CA, USA). Absorbance value was normalized to that in control cells.

Statistical analysis. Statistical analyses were performed using JMP Pro 11.2.0 software (SAS Institute Inc.). Tukey's test was performed to analyze the differences between multiple groups. P-values $<0.05$ were considered statistically significant.

\section{Results}

Identification of candidate substrate proteins phosphorylated by Dclkl, using protein microarray. To identify proteins phosphorylated by Dclk1, we used a protein microarray that features highly specific antibodies against 269 phosphorylated proteins that play important roles in cancer signaling pathways. Cell lysates were prepared from MIA Paca2 cells treated with either DMSO or LRRK, as well as PANC-1 cells transfected with either Non-target or Dclk1 siRNA. Tables I and II show cancer-related phosphorylated proteins with expression levels decreased by $>50 \%$ in Dclk1-inhibited pancreatic cancer cells. The expression levels of p-Chk1 and p-cdc25A, 
A

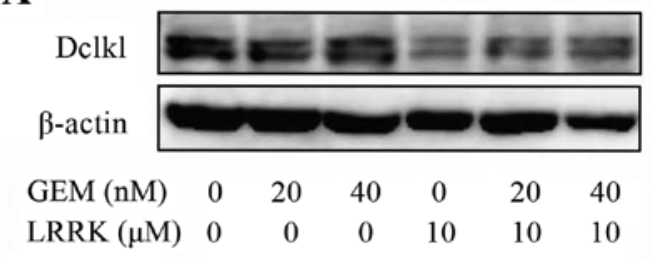

C

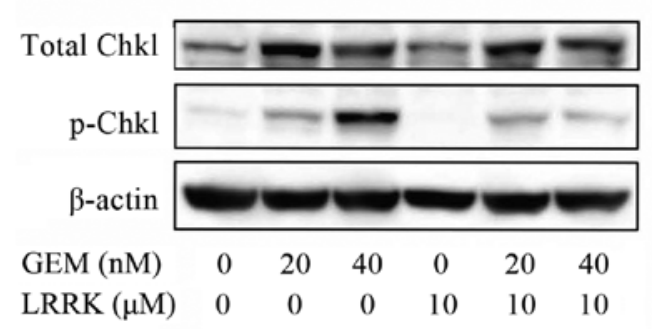

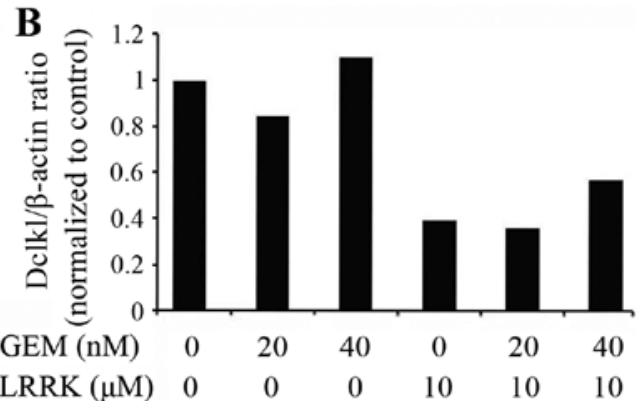

D

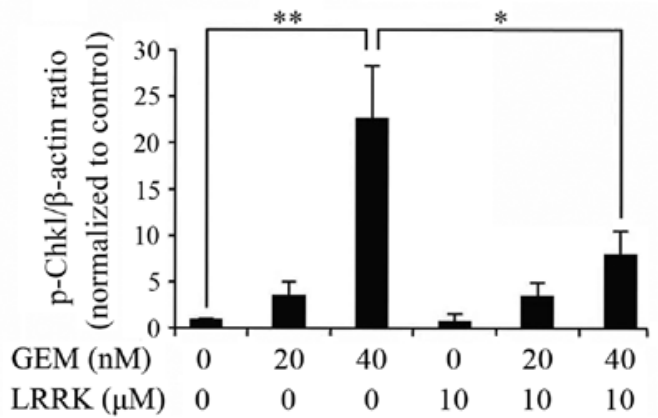

Figure 2. Effect of DMSO, GEM, LRRK treatment, or the combined treatment with GEM and LRRK on the expression of p-Chk1. (A) Cell lysates were prepared from MIA Paca2 cells treated with DMSO, GEM $(20$ or $40 \mathrm{nM})$, LRRK $(10 \mu \mathrm{M})$ treatment, or the combined treatment with GEM $(20$ or $40 \mathrm{nM})$ and LRRK $(10 \mu \mathrm{M})$ for $48 \mathrm{~h}$, and the expression levels of Dclk1 and $\beta$-actin were detected by western blotting. $\beta$-actin was used to assess the total amount of proteins loaded on the gel. (B) The intensity of each band was quantified using ImageJ software. The ratio of Dclk1 to $\beta$-actin was normalized to that in control cells. (C) Cell lysates were prepared from MIA Paca2 cells treated with DMSO, GEM (20 or $40 \mathrm{nM})$, LRRK $(10 \mu \mathrm{M})$ treatment, or the combined treatment with GEM $(20$ or $40 \mathrm{nM})$ and LRRK $(10 \mu \mathrm{M})$ for $48 \mathrm{~h}$, and the expression levels of Chk1, p-Chk1, and $\beta$-actin were detected by western blotting. $\beta$-actin was used to assess the total amount of proteins loaded on the gel. (D) The intensity of each band was quantified using ImageJ software. The ratio of p-Chk1 to $\beta$-actin was normalized to that in control cells. Each bar represents the mean $\pm \mathrm{SE}$ of three experiments. ${ }^{*} \mathrm{P}<0.05{ }^{*}{ }^{* *} \mathrm{P}<0.01$, significantly different.

a downstream protein of $\mathrm{p}-\mathrm{Chk} 1$, were reduced in both Dclk1inhibited PANC-1 and MIA Paca2 pancreatic cancer cells. These proteins belong to the ATR pathway and regulate the cell cycle checkpoint. The array images of p-cdc25A, p-Chk1, and $\beta$-actin in MIA Paca2 cells treated with either DMSO or LRRK are shown (Fig. 1A). LRRK treatment tended to decrease Dclk1 expression compared with DMSO treatment (Fig. 1B). Thus, these results indicate that Dclk1 is involved in the regulation of the cell cycle checkpoint through phosphorylation of cdc25A and Chk1.

GEM induces phosphorylation of Chkl, and combined treatment with GEM and LRRK significantly decreases p-Chkl expresssion. To evaluate the individual and combined effects of GEM and LRRK treatment on phosphorylation of Chk1, MIA Paca2 cells were treated with DMSO, GEM, LRRK treatment, or the combined treatment with GEM and LRRK for $48 \mathrm{~h}$ and analyzed by western blotting. Dclk1 expression tended to be decreased following LRRK treatment and remain unchanged following GEM treatment compared with DMSO treatment (Fig. 2A and B). As expected, GEM treatment significantly induced Chk1 phosphorylation in MIA Paca2 cells (Fig. 2C and D). Notably, combined treatment with GEM and LRRK significantly reduced the expression of p-Chk1 compared with GEM treatment alone (Fig. 2C and D).

Combined treatment with GEM and LRRK abolished GEM-induced cell cycle arrest and increased DNA damage compared with GEM or LRRK treatment alone. To evaluate
Table III. The proportion of $\gamma$-H2AX-positive cells in each phase of the cell cycle.

\begin{tabular}{lrrrrr}
\hline Treatment & sub-G1 & G1 & \multicolumn{1}{c}{ S } & G2/M & Total \\
\hline Control & & & & & \\
$\gamma$-H2AX (+) & 0.81 & 1.37 & 0.98 & 2.49 & 5.65 \\
$\gamma$-H2AX (-) & 4.01 & 53.81 & 12.49 & 24.04 & 94.35 \\
$\quad$ Total & 4.82 & 55.18 & 13.47 & 26.53 & 100.00 \\
GEM & & & & & \\
$\gamma$-H2AX (+) & 0.66 & 11.19 & 27.37 & 29.14 & 68.36 \\
$\gamma$-H2AX (-) & 1.32 & 12.00 & 15.81 & 2.51 & 31.64 \\
Total & 1.98 & 23.19 & 43.18 & 31.65 & 100.00 \\
LRRK & & & & & \\
$\gamma$-H2AX (+) & 0.95 & 16.42 & 5.85 & 29.79 & 53.01 \\
$\gamma$-H2AX (-) & 1.65 & 28.53 & 4.41 & 12.40 & 46.99 \\
Total & 2.60 & 44.95 & 10.26 & 42.19 & 100.00 \\
GEM + LRRK & & & & & \\
$\gamma$-H2AX (+) & 0.61 & 38.10 & 13.35 & 28.76 & 80.82 \\
$\gamma$-H2AX (-) & 0.48 & 16.02 & 1.56 & 1.12 & 19.18 \\
Total & 1.09 & 54.12 & 14.91 & 29.88 & 100.00 \\
\hline
\end{tabular}

the individual and combined effects of GEM and LRRK treatment on cell cycle progression and DNA damage, we 


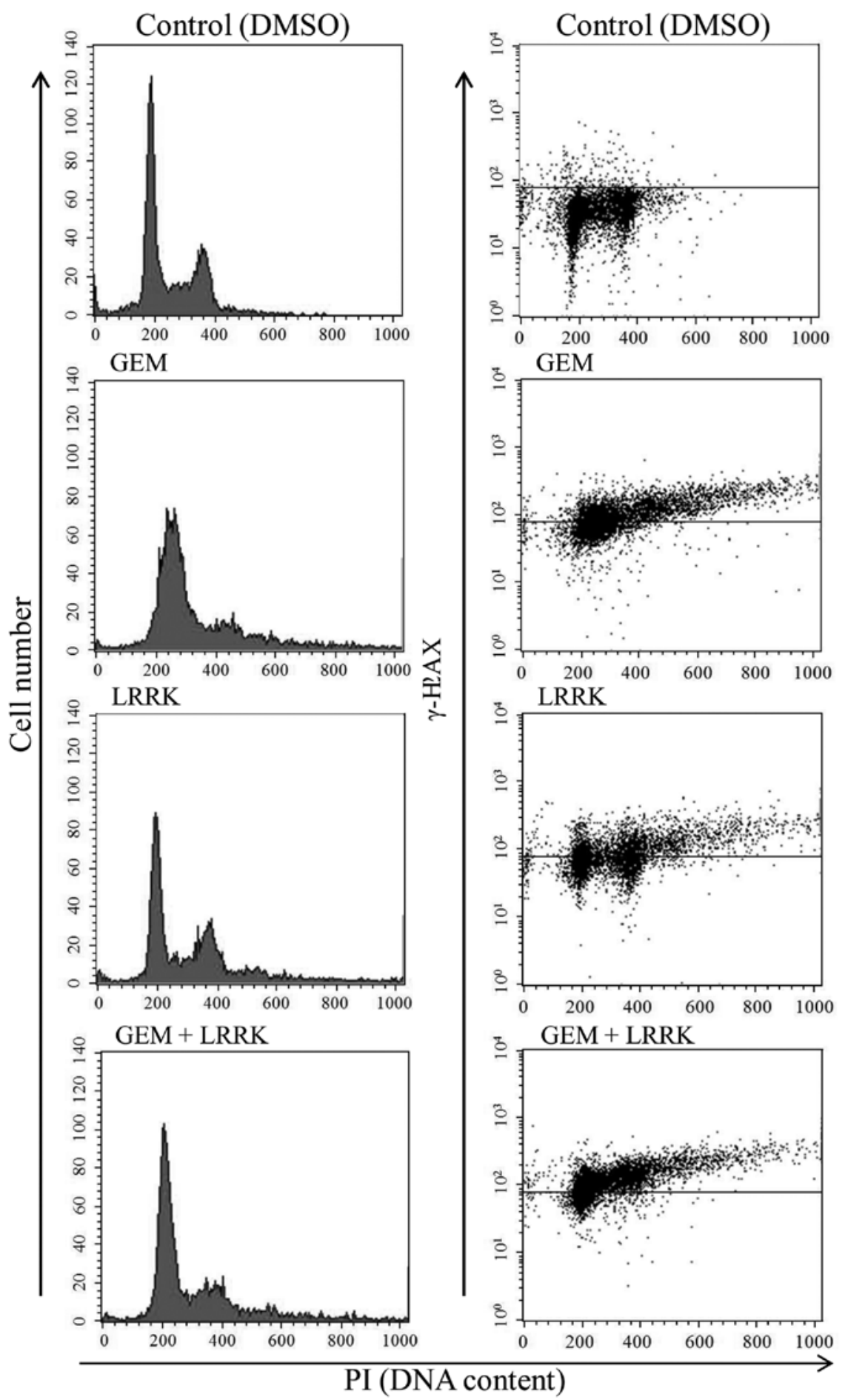

Figure 3. Effect of DMSO, GEM, LRRK treatment, or the combined treatment with GEM and LRRK on cell cycle and DNA damage. After $24 \mathrm{~h}$ serum starvation, MIA Paca2 cells were treated with DMSO, GEM $(40 \mathrm{nM})$, LRRK $(10 \mu \mathrm{M})$ treatment, or the combined treatment with GEM $(40 \mathrm{nM})$ and LRRK $(10 \mu \mathrm{M})$ for $24 \mathrm{~h}$, followed by FACS analyses. The horizontal line shows the intensity of PI. The vertical line shows cell number (left panel), and $\gamma$-H2AX expression level (right panel). Representative results of FACS analyses are shown.

performed flow cytometry analyses of cells stained with PI and $\gamma$-H2AX, respectively. After serum starvation for $24 \mathrm{~h}$, most MIA Paca2 cells were observed at G0/G1 phase of the cell cycle (data not shown). As previously reported, individual treatment with GEM induced cell cycle arrest at S phase (3) and increased the number of $\gamma$-H2AX-positive cells (Fig. 3 and Table III). Individual treatment with LRRK proceeded cell cycle and increased the number of $\gamma$-H2AX-positive cells
(Fig. 3 and Table III). Notably, combined treatment with GEM and LRRK allowed cell cycle progression without arresting at $S$ phase and increased the number of $\gamma-\mathrm{H} 2 \mathrm{AX}$-positive cells compared with individual treatments with GEM or LRRK (Fig. 3 and Table III).

LRRK treatment alone, and combined treatment with GEM and LRRK induces caspase-3 activation and PARPI cleavage. 
A

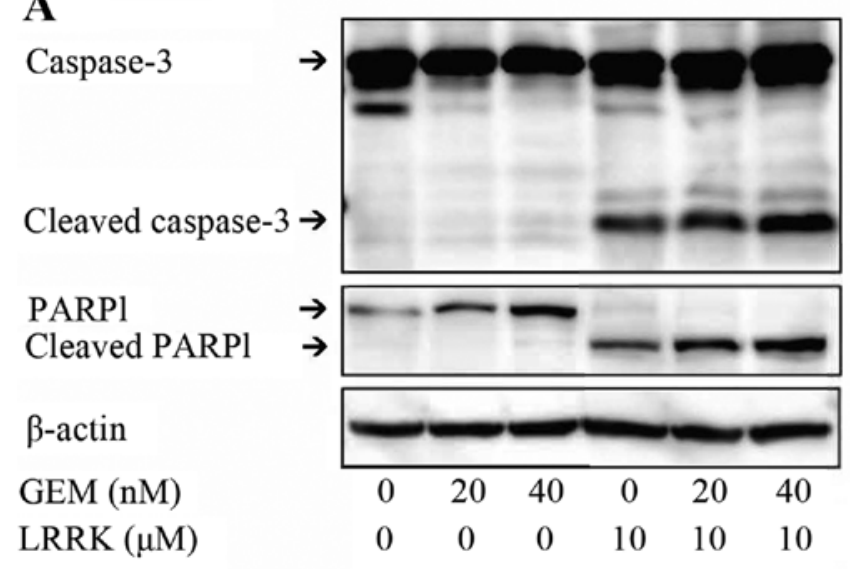

B

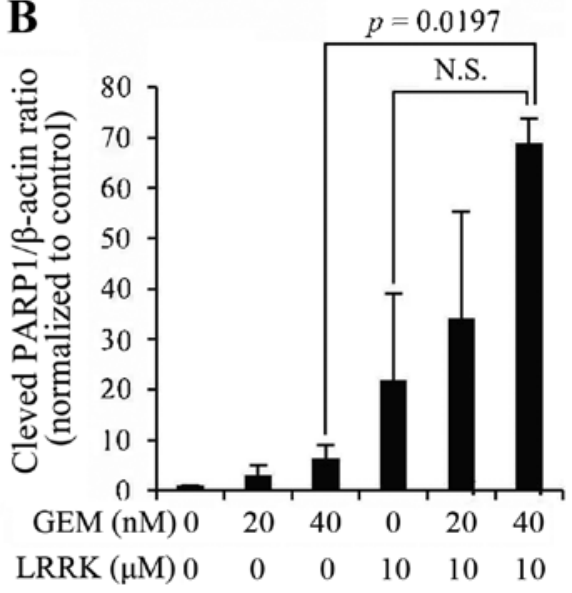

Figure 4. Effect of DMSO, GEM, LRRK treatment, or the combined treatment with GEM and LRRK on caspase-3 activation and PARP1 cleavage. (A) Cell lysates were prepared from MIA Paca2 cells treated with DMSO, GEM (20 or $40 \mathrm{nM})$, LRRK (10 $\mu \mathrm{M})$ treatment, or the combined treatment with GEM $(20$ or $40 \mathrm{nM})$ and LRRK $(10 \mu \mathrm{M})$ for $48 \mathrm{~h}$, and the expression levels of caspase-3, cleaved caspase-3, PARP1, cleaved PARP1, and $\beta$-actin were detected by western blotting. $\beta$-actin was used to assess the total amount of proteins loaded on the gel. (B) The intensity of each band was quantified using ImageJ software. The ratio of cleaved PARP1 to $\beta$-actin was normalized to that in control cells. Each bar represents the mean \pm SE of three experiments. N.S., no significant difference.

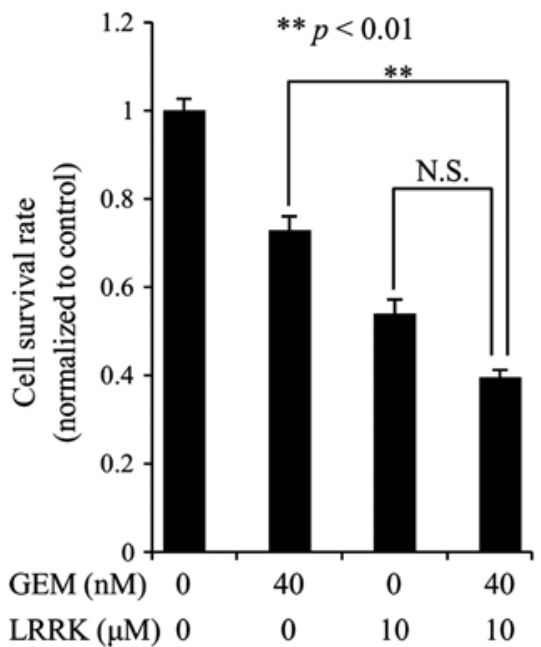

Figure 5. Effect of DMSO, GEM, LRRK treatment, or the combined treatment with GEM and LRRK on cell survival. MIA Paca2 cells were treated with DMSO, GEM $(40 \mathrm{nM})$, LRRK $(10 \mu \mathrm{M})$ treatment, or the combined treatment with GEM $(40 \mathrm{nM})$ and LRRK $(10 \mu \mathrm{M})$ for $72 \mathrm{~h}$, followed by cell survival assay to assess cell survival rate. Cell survival rate was normalized to that in control cells. Each bar represents the mean \pm SE of three experiments. ${ }^{* *} \mathrm{P}<0.01$, significantly different. N.S., no significant difference.

To evaluate the individual and combined effects of GEM and LRRK treatment on apoptosis, MIA Paca2 cells were treated with DMSO, GEM, LRRK treatment, or the combined treatment with GEM and LRRK for $48 \mathrm{~h}$ and analyzed by western blotting. Notably, individual treatment with LRRK, and combined treatment with GEM and LRRK induced caspase-3 activation and PARP1 cleavage, although individual treatment with GEM almost did not (Fig. 4A). PARP1 cleavage upon combined treatment with GEM and LRRK significantly increased compared with that upon GEM treatment alone and tended to increase compared with that upon LRRK treatment alone (Fig. 4B). Notably, GEM treatment alone tended to increase the expression of intact PARP1, a substrate protein of activated caspase- 3 , and combined treatment with GEM and LRRK tended to increase cleaved caspase-3 levels. These are reasons why combined treatment with GEM and LRRK tended to increase cleaved PARP1 levels.

Combined treatment with GEM and LRRK significantly decrease survival rate of MIA Paca2 cells compared to individual treatment with GEM. To evaluate the individual and combined effects of GEM and LRRK treatment on MIA Paca2 cell survival, we performed cell survival assay following DMSO, GEM, LRRK treatment, or the combined treatment with GEM and LRRK. Individual treatment with GEM or LRRK decreased cell survival to a modest extent (Fig. 5). Combined treatment with GEM and LRRK significantly decreased cell survival compared to individual treatment with GEM and tended to decrease cell survival compared to individual treatment with LRRK (Fig. 5).

\section{Discussion}

In this study, we identified candidate substrate proteins phosphorylated by Dclk1, using a cancer-related phosphorylated protein microarray of Dclk1-inhibited MIA Paca2 cells. P-cdc25A and p-Chk1 proteins were included among the phosphorylated proteins whose expression levels were decreased by $>50 \%$ through functional inhibition of Dclk1. These proteins belong to the ATR pathway, which regulates the cell cycle checkpoint. Chk1 is phosphorylated by activated ATR, and p-Chk1 phosphorylates cdc25A, leading to the induction of cell cycle arrest. That is, p-Chk1 is located upstream of $\operatorname{cdc} 25 \mathrm{~A}$, and cdc25A is, therefore, a substrate protein of $\mathrm{p}$-Chk1. Thus, we focused on Chk1 as a candidate substrate protein phosphorylated by Dclk1. As expected, GEM-induced p-Chk1 expression level is significantly decreased by Dclk1 inhibition, and combined treatment with GEM and LRRK allowed cell cycle progression without arresting at $\mathrm{S}$ phase. Furthermore, combined treatment increased DNA damage, apoptosis, and cell death compared with those upon individual treatment with GEM. Based on 
these results, we propose that the mechanism by which the combined treatment increased cell death is as follows. Dclk1 inhibition decreased GEM-induced p-Chk1 expression, and the cell cycle checkpoint was impaired. Consequently, cell cycle proceeded without repairing damaged DNA at the arrested $\mathrm{S}$ phase, leading to cell death due to lethal chromosome instability. Furthermore, $\mathrm{O}^{\prime}$ Connell et al recently reported that the short form of Dclk1 is mainly expressed in human colon cancer cells, whereas the long form is mainly expressed in normal colon cells (25). In this study, we detected the expression of the short form of Dclk1 in MIA Paca 2 cells. To determine whether the expression of the short form of Dclk1 in human pancreatic cancer cells is universal, further studies will be needed to investigate which form of Dclk1 is expressed in many other human pancreatic cancer cell lines, pancreatic cancer tissues, and normal human pancreatic cells.

In conclusion, combined treatment with GEM and a Dclk1 inhibitor, LRRK, significantly reduced the cell survival rate compared to individual treatment with GEM, by impairing the cell cycle checkpoint. Targeting Dclk1, in combination with GEM treatment, might offer an excellent opportunity for future pancreatic cancer treatments.

\section{Acknowledgements}

We would like to thank Professor Yoichi Mizukami (Chairman of the Center for Gene Research at Yamaguchi University) for useful suggestions on cell cycle analysis. We also thank Ms. Yukari Hironaka for technical assistance. This study was supported by Grant-in-Aids for Young Scientific Research (B) (16K19932 to Y.T.) from Japan Society for the Promotion of Science (JSPS) and the Onkochishin Project Grant (to A.N.) from Yamaguchi University.

\section{References}

1. Siegel RL, Miller KD and Jemal A: Cancer Statistics, 2017. CA Cancer J Clin 67: 7-30, 2017.

2. Kamisawa T, Wood LD, Itoi T and Takaori K: Pancreatic cancer. Lancet 388: 73-85, 2016.

3. Shi Z, Azuma A, Sampath D, Li YX, Huang P and Plunkett W: S-Phase arrest by nucleoside analogues and abrogation of survival without cell cycle progression by 7-hydroxystaurosporine. Cancer Res 61: 1065-1072, 2001.

4. Karnitz LM, Flatten KS, Wagner JM, Loegering D, Hackbarth JS, Arlander SJH, Vroman BT, Thomas MB, Baek YU, Hopkins KM, et al: Gemcitabine-induced activation of checkpoint signaling pathways that affect tumor cell survival. Mol Pharmacol 68: 1636-1644, 2005.

5. Morgan MA, Parsels LA, Parsels JD, Mesiwala AK, Maybaum J and Lawrence TS: Role of checkpoint kinase 1 in preventing premature mitosis in response to gemcitabine. Cancer Res 65: 6835-6842, 2005.

6. Parsels LA, Morgan MA, Tanska DM, Parsels JD, Palmer BD, Booth RJ, Denny WA, Canman CE, Kraker AJ, Lawrence TS, et al: Gemcitabine sensitization by checkpoint kinase 1 inhibition correlates with inhibition of a Rad51 DNA damage response in pancreatic cancer cells. Mol Cancer Ther 8: 45-54, 2009.

7. Venkatesha VA, Parsels LA, Parsels JD, Zhao L, Zabludoff SD, Simeone DM, Maybaum J, Lawrence TS and Morgan MA: Sensitization of pancreatic cancer stem cells to gemcitabine by Chk1 inhibition. Neoplasia 14: 519-525, 2012.

8. Montano R, Thompson R, Chung I, Hou H, Khan N and Eastman A: Sensitization of human cancer cells to gemcitabine by the Chk1 inhibitor MK-8776: Cell cycle perturbation and impact of administration schedule in vitro and in vivo. BMC Cancer 13: 604, 2013.
9. Koh SB, Courtin A, Boyce RJ, Boyle RG, Richards FM and Jodrell DI: CHK1 inhibition synergizes with gemcitabine initially by destabilizing the DNA replication apparatus. Cancer Res 75: 3583-3595, 2015.

10. Barnard D, Diaz HB, Burke T, Donoho G, Beckmann R, Jones B, Barda D, King C and Marshall M: LY2603618, a selective CHK1 inhibitor, enhances the anti-tumor effect of gemcitabine in xenograft tumor models. Invest New Drugs 34: 49-60, 2016.

11. Seto T, Esaki T, Hirai F, Arita S, Nosaki K, Makiyama A, Kometani T, Fujimoto C, Hamatake M, Takeoka H, et al: Phase I, dose-escalation study of AZD7762 alone and in combination with gemcitabine in Japanese patients with advanced solid tumours. Cancer Chemother Pharmacol 72: 619-627, 2013.

12. Sausville E, Lorusso P, Carducci M, Carter J, Quinn MF, Malburg L, Azad N, Cosgrove D, Knight R, Barker P, et al: Phase I dose-escalation study of AZD7762, a checkpoint kinase inhibitor, in combination with gemcitabine in US patients with advanced solid tumors. Cancer Chemother Pharmacol 73: 539-549, 2014.

13. Daud AI, Ashworth MT, Strosberg J, Goldman JW, Mendelson D, Springett G, Venook AP, Loechner S, Rosen LS, Shanahan F, et al: Phase I dose-escalation trial of checkpoint kinase 1 inhibitor MK-8776 as monotherapy and in combination with gemcitabine in patients with advanced solid tumors. J Clin Oncol 33: 1060-1066, 2015.

14. Doi T, Yoshino T, Shitara K, Matsubara N, Fuse N, Naito Y, Uenaka K, Nakamura T, Hynes SM and Lin AB: Phase I study of LY2603618, a CHK1 inhibitor, in combination with gemcitabine in Japanese patients with solid tumors. Anticancer Drugs 26: 1043-1053, 2015

15. Calvo E, Braiteh F, Von Hoff D, McWilliams R, Becerra C, Galsky MD, Jameson G, Lin J, McKane S, Wickremsinhe ER, et al: Phase I study of CHK1 inhibitor LY2603618 in combination with gemcitabine in patients with solid tumors. Oncology 91: 251-260, 2016.

16. Goto H, Izawa I, Li Ping and Inagaki M: Novel regulation of checkpoint kinase 1: Is checkpoint kinase 1 a good candidate for anti-cancer therapy? Cancer Sci 103: 1195-1200, 2012.

17. Lin PT, Gleeson JG, Corbo JC, Flanagan L and Walsh CA: DCAMKL1 encodes a protein kinase with homology to doublecortin that regulates microtubule polymerization. J Neurosci 20 : 9152-9161, 2000.

18. Omori Y, Suzuki M, Ozaki K, Harada Y, Nakamura Y, Takahashi E and Fujiwara T: Expression and chromosomal localization of KIAA0369, a putative kinase structurally related to Doublecortin. J Hum Genet 43: 169-177, 1998.

19. Mohammed A, Janakiram NB, Madka V, Brewer M, Ritchie RL, Lightfoot S, Kumar G, Sadeghi M, Patlolla JMR, Yamada HY, et al: Targeting pancreatitis blocks tumor-initiating stem cells and pancreatic cancer progression. Oncotarget 6: 15524-15539, 2015.

20. Sureban SM, May R, Qu D, Weygant N, Chandrakesan P, Ali N, Lightfoot SA, Pantazis P, Rao CV, Postier RG, et al: DCLK1 regulates pluripotency and angiogenic factors via microRNAdependent mechanisms in pancreatic cancer. PLoS One 8: e73940, 2013

21. Sureban SM, May R, Lightfoot SA, Hoskins AB, Lerner M, Brackett DJ, Postier RG, Ramanujam R, Mohammed A, Rao CV, et al: DCAMKL-1 regulates epithelial-mesenchymal transition in human pancreatic cells through a miR-200a-dependent mechanism. Cancer Res 71: 2328-2338, 2011.

22. Ito $\mathrm{H}$, Tanaka S, Akiyama $\mathrm{Y}$, Shimada S, Adikrisna R, Matsumura S, Aihara A, Mitsunori Y, Ban D, Ochiai T, et al: Dominant expression of DCLK1 in human pancreatic cancer stem cells accelerates tumor invasion and metastasis. PLoS One 11: e0146564, 2016.

23. Sureban SM, May R, Weygant N, Qu D, Chandrakesan P, Bannerman-Menson E, Ali N, Pantazis P, Westphalen CB, Wang TC, et al: XMD8-92 inhibits pancreatic tumor xenograft growth via a DCLK1-dependent mechanism. Cancer Lett 351: 151-161, 2014.

24. Weygant N, Qu D, Berry WL, May R, Chandrakesan P, Owen DB, Sureban SM, Ali N, Janknecht R and Houchen CW: Small molecule kinase inhibitor LRRK2-IN-1 demonstrates potent activity against colorectal and pancreatic cancer through inhibition of doublecortin-like kinase 1. Mol Cancer 13: 103, 2014.

25. O'Connell MR, Sarkar S, Luthra GK, Okugawa Y, Toiyama Y, Gajjar AH, Qiu S, Goel A and Singh P: Epigenetic changes and alternate promoter usage by human colon cancers for expressing DCLK1-isoforms: Clinical implications. Sci Rep 5: 14983, 2015. 